\title{
Design of the Large Rotary Wheel Declining Nozzle Range Theory Research Based on Fluent Simulation Software
}

\author{
Fang Buling ${ }^{1}$, Deng $\mathrm{Jiao}^{2}$, Qi Songtao ${ }^{3}$ \\ ${ }^{1}$ China, Nanjing,Professor, Key Laboratory of Efficient Irrigation-Drainage and Agricultural \\ Soil-Water Environment in Southern China, Hohai University, The College of Water Conservancy \\ and Hydropower Engineering,210098
}

${ }^{2}$ China, Nanjing,Master, Key Laboratory of Efficient Irrigation-Drainage and Agricultural Soil-Water Environment in Southern China, Hohai University, The College of Water Conservancy and Hydropower Engineering,210098

${ }^{3}$ China, Nanjing,Engineer, Nanjing ShengQuan Institute for water-saving irrigation

afbling@163.com, bdengj1225@163.com, ${ }^{\circ} 54741469 @ q q . c o m$

Keywords: Big rotary wheel micro sprinkler; Range; The theoretical calculation; simulation.

\begin{abstract}
This paper studies the micro sprinkler with two rotation hyperboloid passage of large rotary wheel revolving body. Using fluent fluid mechanics calculation software velocity distribution simulation analysis for five different diameter and seven different water elevation rotating body fluid movement, obtains turning wheel outlet velocity. Then using Newton'ssecond law and aerodynamics principle of droplets in the air operation range theory calculation, through the design of micro nozzle for plastic mould products forming and experimental verification, It has found that the method can better predict micro nozzle range and has acertain guiding significance on the micro nozzle design. Through field application, good results have been achieved.
\end{abstract}

\section{Introduction}

In the Micro sprinkler irrigation system, micro sprinkler range is an important performance index. If the range is small, the whole network will be denser after combination, more Micro spray nozzle will be needed, As a result, initial investment will increase. Micro spray system cost will be greatly saved by increasing the micro sprinkler range by a reasonable amount, This will promote popularization of micro-irrigation engineering and application for large areas ${ }^{[1][2][3]}$. Presently, the common rotating range in the home market is from 2 to 4 meters, whereas a few foreign manufacturers have reached a high of 5 to 6 meters. The $4 \mathrm{~m}$ range of micro spray nozzle's rotating body are mostly of the unilateral type, in which the spray's ability to spray uniformly along the direction is poor. Often, the water is sprayed more to the edges, and less to the centre, thereby forming a hollow circle. This limits the use of the micro sprinkler. To make the rotating spraying range large and the spraying width direction along the spray distribution uniform are difficult problems in the micro sprinkler research. The traditional method is employed for production when a new micro sprinkler is designed, and then the size of its range is tested by experimentation. This is both time-consuming and expensive. Lastly, it is difficult to find a good variety of micro sprinkler.

Since the 1920s, the range of sprinkler has been paid close attention, and many studies have been made by scholars at home and abroad. Many scholars have chosen the early Impact Drive Sprinkler as research object. For instance, Silva ${ }^{[4]}$, Thompson ${ }^{[5]}$, and others studied the droplet evaporation after the export in Impact Drive Sprinkler by the aerodynamics principle. Many scholars draw a variety of semi-empirical formula of the Impact Drive Sprinkler by experiments, such as Chang Wenhai, Gan Zhemin, jarvelin, Feng Chuanda's formula and so on. Tuo Yunfei ${ }^{[6]}$ divided sprinkler droplet into horizontal, vertical ascent and descent according to Newton's Second Law and the theory of hydraulics, calculated the water droplets in the air movement time and found the sprinkler range formula. Wang Bolei ${ }^{[7]}$ analyzed PY2 Impact Drive Sprinkler in the case of the wind of sprinkler nozzle range formula through aerodynamics and Newton's second law. For small flow micro nozzle, water flow in the rotary wheel movement is more complex. No relevant 
documentation of this kind of research could be found at home and abroad. This paper studies a large rotary wheel micro sprinkler structure. By using the fluent fluid dynamics simulation software to simulate flow movement of the wheel, reach the maximum velocity at the exit, and then analysis of the movement mechanism of droplet spin round exit by the use of Newton's second law and the principle of aerodynamics, its effective range was calculated.

\section{The working principle and structural characteristics}

In this paper, the study of the rotary wheel micro sprinklers consists of three parts, the bracket, the nozzle and the rotating body. When used, the water flow from the pressurized pipes to the spray nozzle, because of nozzle contraction, flow acceleration, thereby forming a high-speed flow impact rotary body. The tapered plastic parts rotating body is a large rotating wheel with two hyperboloid of revolution runner. The structure is shown in Figure 1. The micro nozzle rotation structure is larger, and the speed is slow when spraying. The water flow can be made steady in the diversion tank, and thrown into the air to form large range spray rate.

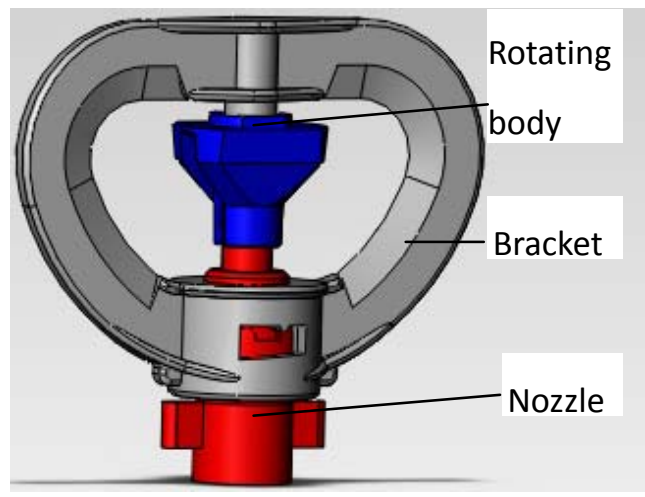

Figure 1 the large rotary wheel micro sprinkler

\section{Analysis and Calculation of internal flow velocities of the rotating body}

The micro sprinklers structure is small, and the water flow through the spray nozzle to the rotary body to make it rotated, therefore the interaction between rotating body rotating and flow movement is more complex. It is more difficult to obtain the runner outlet flow rate directly with theoretical calculations. This paper uses the Fluent computational fluid dynamics software simulation of the nozzle internal water movement to obtain velocity contours and exit velocity under ideal conditions.

The micro sprinkler designed five different types of nozzles, aperture were 1.5, 1.8, 2.0, 2.5, and $3.0 \mathrm{~mm}$. The nozzles are designed for seven forms of rotating body of different aperture outlet elevation angle of $8^{\circ}, 12^{\circ}, 15^{\circ}, 18^{\circ}, 23^{\circ}, 27^{\circ}$, and $30^{\circ}$.

The rotation micro sprinkler design has a working pressure of $200 \mathrm{kPa}$. Micro-sprinklers on each model make the simulation of the flow inside the flow channel movement, the internal flow channel of the rotary body shown in Figure 2 (a) to (e). To Gambit software meshing of the water channel, select the import and export sectional, import in Fluent, set the inlet pressure to $200 \mathrm{kPa}$, export conditions for $0 \mathrm{kPa}$, wall friction is ignored, the rotary body inclination angle is $30^{\circ}$, the simulation speed cloud for different aperture micro-sprinkler as shown in Figure 2. The transition of blue to red in the figure represents the gradual increase of the speed.

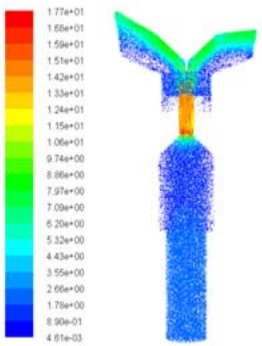

(a)

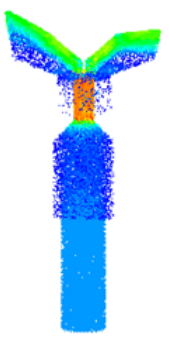

(b)

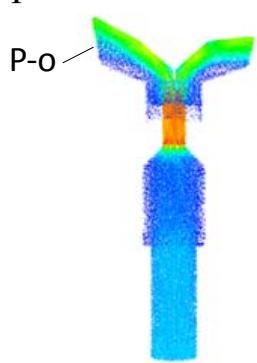

(c)

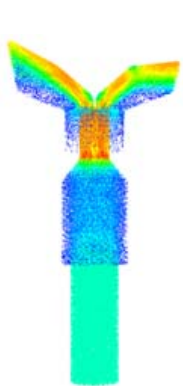

(d)

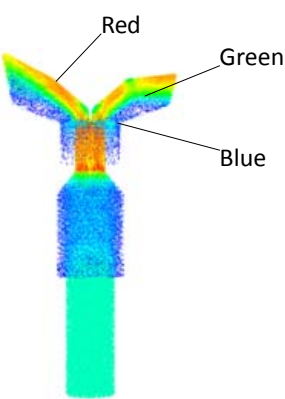

(e)

Figure 2 Inclination of $30^{\circ}$ nozzle diameter micro-Sprinklers speed contours
(a) Diameter of $1.5 \mathrm{~mm}$
(b) Diameter of $1.8 \mathrm{~mm}$
(c) Diameter of $2.0 \mathrm{~mm}$
(d) Diameter of $2.5 \mathrm{~mm}$
(e) Diameter of $3.0 \mathrm{~mm}$

Under the rated working pressure $200 \mathrm{kPa}$, the maximum analog exit velocity of each model micro sprinkler is shown in Table 1. As the results of the simulation have shown, when the 
micro-spray nozzle hole diameter increases, the flow channel speed of the rotating body gradually increases.

\section{The theoretical analysis and calculation of the micro Sprinklers range}

After the micro-sprinkler water is injected from the flow channel of the rotating body, due to the resistance of the air and entrainment, the micro-sprinkler water is gradually crushed into droplets of different sizes, and at the same time due to the interaction of the air with the water droplets, the trajectory of the water droplets is impacted.

During the process of spraying, small water droplets are sprayed into close vicinity and large water droplets are sprayed to further distances. Mugele and Evans ${ }^{[8]}$ use the upper limit of the normal distribution to describe the distribution of Sprinklers' droplets, whereas Liu Haijun ${ }^{[9]}$ processed the experimental data by using regression analysis. Empirical formula for the Sprinklers largest droplet diameter is as follows:

$$
D=2.3096 d^{0.831} P^{-0.257} \quad(\mathrm{R}=0.8)
$$

In the above formula: D - Maximum droplet diameter,in $\mathrm{mm}$,

$\mathrm{d}$ - Nozzle diameter,in $\mathrm{mm}, \quad \mathrm{P}$ - Working pressure,in $\mathrm{kPa}$

When a drop of water injects from the rotary body rotation path, interacts with the air,assuming that water droplets remains approximately spherical in the air during exercise, the amount of evaporation of the water droplets is ignored, analysis of the process of the flow of water droplets three-dimensional motion from the rotating body path exit and the exit to the floor, its movement is described as:

$$
\begin{array}{ll}
\text { X direction: } & m \frac{\partial^{2} x}{\partial t^{2}}=-f\left[\frac{\partial_{x}}{\partial_{t}}\right]^{2} \\
\text { Y direction: } & m \frac{\partial^{2} y}{\partial t^{2}}=-f\left[\frac{\partial_{y}}{\partial_{t}}\right]^{2}
\end{array}
$$

$\mathrm{Z}$ direction, as the resistance to movement of the droplets is always opposite to the direction of movement, gravity direction is the opposite direction of the rising segment with the speed. For the descent stage, the direction and speed are the same. The two segments are described as:

Rising segment:

$$
m \frac{\partial^{2} z}{\partial t^{2}}=-f\left[\frac{\partial_{z}}{\partial_{t}}\right]^{2}-m g
$$

Descent stage:

$$
m \frac{\partial^{2} z}{\partial t^{2}}=f\left[\frac{\partial_{z}}{\partial_{t}}\right]^{2}-m g
$$

The initial and boundary conditions of the equation (2) to (5) as:

$$
\begin{array}{lc}
\left.x\right|_{t=0}=0 & \left.v_{x}\right|_{t=0}=v_{o x} \\
\left.y\right|_{t=0}=0 & \left.v_{y}\right|_{t=0}=v_{o y} \\
\left.z\right|_{t=0}=h & \left.v_{z}\right|_{t=0}=v_{o z} \\
\left.z\right|_{t=t_{2}}=0 & \left.v_{z 0^{\prime}}\right|_{t=t_{1}}=0
\end{array}
$$

In the formula (2), from $v_{x}=\frac{\partial_{x}}{\partial_{t}}$ and initial conditions (6) can be obtained:

$m \frac{\partial_{v x}}{\partial_{t}}=-f v_{x}^{2}$

Combining above formulas, the following can be obtained: 


$$
\begin{aligned}
& v_{x}=\frac{v_{0 x} m}{m+f v_{0 x} t} \\
& x=\frac{m}{f} \ln \left|\frac{v_{0 x} f}{m} t+1\right|
\end{aligned}
$$

Similarly, the Y direction solution:

$$
y=\frac{m}{f} \ln \left|\frac{v_{0 y} f}{m} t+1\right|
$$

Rising section in the Z-axis direction, equation the initial and boundary conditions (9) into the formula (3) can be integrated:

$$
v_{z}=\sqrt{\frac{m g}{f}} \tan |\arctan | \sqrt{\frac{f}{m g}} v_{0 z}\left|-t \sqrt{\frac{g f}{m}}\right|
$$

So $\mathrm{v}_{\mathrm{z}}=0$, and obtain the water droplets ascent exercise time

$$
t_{1}=\sqrt{\frac{m}{f g}} \arctan \left|\sqrt{\frac{f}{m g}} v_{0 z}\right|
$$

For the descent stage, the speed is same as the direction of

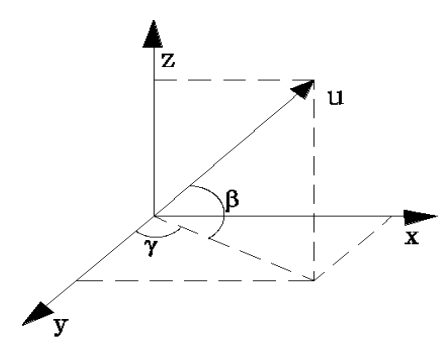

Figure 3 The exit velocity Diagram of the rotating body gravity, take the initial conditions into the formula (4) can be integrated:

$$
v_{z}=\sqrt{\frac{m g}{f}} \cdot \frac{1+e^{-2 t \sqrt{\frac{g f}{m}}}}{1-e^{-2 t \sqrt{\frac{g f}{m}}}}
$$

Combining above formulas, the following can be obtained:

$$
z=\sqrt{\frac{g m}{f}}+\frac{m}{f} \ln \left|1+2 t \sqrt{\frac{g f}{m}}\right|
$$

So inutting $\mathrm{z}=0$ into the above formula make the water droplets falling segmental motion time available:

$$
t_{2}=\frac{1}{2} \sqrt{\frac{m}{f g}} \cdot\left(e^{-\sqrt{\frac{g f}{m}}}+1\right)
$$

By the formula (12) (14) can be obtained motion total time $\mathrm{T}=\mathrm{t}_{1}+\mathrm{t}_{2}$, thereby calculated the displacement value of (10) (11) where $\mathrm{X}$ and $\mathrm{Y}$ directions, obtained the displacement of water droplets movement, which is the range $\mathrm{R}$ :

$$
R=\sqrt{x^{2}(T)+y^{2}(T)}
$$

In the formula: $\mathrm{x}, \mathrm{y}, \mathrm{z}, \mathrm{v}_{\mathrm{x}}, \mathrm{v}_{\mathrm{y}}, \mathrm{v}_{\mathrm{z}^{---}}$were droplets at any moment $\mathrm{t}$, displacement and velocity, respectively in the coordinate axis of the projector, $\mathrm{m}, \mathrm{m} / \mathrm{s}$

m--droplet mass, $\mathrm{kg}, \mathrm{m}=\frac{\pi D^{3} \rho_{\mathrm{w}}}{6}, \mathrm{t}$ - the water droplets sports time, $\mathrm{s}, \mathrm{g}$-acceleration of gravity,take $9.81 \mathrm{~m} / \mathrm{s} 2$

f--water droplets and the air coefficient of friction, $\mathrm{kg} / \mathrm{m}$

$$
\begin{aligned}
& f=\psi \rho_{a} D^{2} \quad(\psi=0.18) \\
& \rho_{a}=\left(1293.31-4.96 \mathrm{t}^{\prime}+0.02807 \mathrm{t}^{2}-0.000188 \mathrm{t}^{\prime 3}\right) / 1000
\end{aligned}
$$

In the formula: $t^{\prime}$----air temperature, $25^{\circ} \mathrm{C}$

Water injects from the wheel, where the speed in the direction of the elevation angle of the air is related to spin round flow channel exit angle of elevation. Therefore, by establishing the three-dimensional coordinate system, rotating tangential direction to rotate the body as the $\mathrm{X}$ axis, the direction of the diameter line as the Y-axis and the vertical centerline as a $\mathrm{Z}$ axis, as shown in Figure 3, the flow velocity component can be obtained: 


$$
\begin{aligned}
& v_{0 x}=u \cdot \cos \beta \cdot \cos \gamma \\
& v_{0 y}=u \cdot \cos \beta \cdot \sin \gamma \\
& v_{0 z}=u \cdot \sin \beta
\end{aligned}
$$

Wherein, $u$ is the flow channel at the outlet of the initial speed (the analog maximum speed), $\beta$ is the runner channel exit elevation angle, this design is $30^{\circ} . \gamma$ is the runner declination $13^{\circ}$.

According to the fluent analog, the rotating body channel outlet maximum flow rate is obtained. By the theoretical above analysis and the conditions set, the micro sprinklers range by formula (1) to (15) is calculated, as shown in Table 1.

Table 1 The largest simulation exports speed and spray rate of different models of micro-sprinklers rotating body

\begin{tabular}{|c|c|c|c|c|c|c|c|c|c|c|}
\hline \multirow{2}{*}{$\beta\left(^{\circ}\right)$} & \multicolumn{8}{|c|}{ Nozzle diameter $\mathrm{d}(\mathrm{mm})$} \\
\cline { 2 - 13 } & \multicolumn{2}{|c|}{1.5} & \multicolumn{2}{|c|}{1.8} & \multicolumn{2}{|c|}{2.0} & \multicolumn{2}{|c|}{2.5} & \multicolumn{2}{c|}{3.0} \\
\cline { 2 - 13 } & $\begin{array}{c}\mathrm{u}_{\max } \\
(\mathrm{m} / \mathrm{s})\end{array}$ & $\Phi$ & $\mathrm{u}_{\max }$ & $\Phi$ & $\mathrm{u}_{\max }$ & $\Phi$ & $\mathrm{u}_{\max }$ & $\Phi$ & $\mathrm{u}_{\max }$ & $\Phi$ \\
$(\mathrm{m})$ & $(\mathrm{m} / \mathrm{s})$ & $(\mathrm{m})$ & $(\mathrm{m} / \mathrm{s})$ & $(\mathrm{m})$ & $(\mathrm{m} / \mathrm{s})$ & $(\mathrm{m})$ & $(\mathrm{m} / \mathrm{s})$ & $(\mathrm{m})$ \\
\hline $8^{\circ}$ & 8.549 & 3.94 & 10.477 & 5.15 & 11.736 & 6.00 & 14.309 & 7.86 & 16.068 & 9.54 \\
\hline $12^{\circ}$ & 8.420 & 4.22 & 10.659 & 5.69 & 11.530 & 6.42 & 14.101 & 8.52 & 15.868 & 10.33 \\
\hline $15^{\circ}$ & 8.486 & 4.45 & 10.741 & 5.99 & 11.724 & 6.80 & 14.349 & 9.02 & 16.270 & 10.98 \\
\hline $18^{\circ}$ & 8.337 & 4.53 & 10.380 & 6.01 & 11.683 & 7.01 & 14.222 & 9.24 & 16.042 & 11.19 \\
\hline $23^{\circ}$ & 8.223 & 4.66 & 10.345 & 6.22 & 11.569 & 7.20 & 14.054 & 9.45 & 15.941 & 11.47 \\
\hline $27^{\circ}$ & 8.121 & 4.68 & 10.240 & 6.26 & 11.403 & 7.21 & 12.502 & 9.51 & 12.811 & 11.49 \\
\hline $30^{\circ}$ & 8.129 & 4.72 & 10.243 & 6.29 & 11.519 & 7.30 & 14.124 & 9.61 & 15.934 & 11.61 \\
\hline
\end{tabular}

Seen from Table 1, rotation decline nozzle spray rate $(\varphi=2 R)$ is increasing as the spray hole diameter and the elevation angle of rotating body increas. In order to meet the micro-sprinkler spray uniformity requirements, the single rotating body cannot use only one kind of elevation angle, the elevation angle of the smaller sub-nozzles need to be set to prevent spraying to form a hollow circle.

\section{Large rotating wheel micro sprinklers spraying performance test}

The prototype of the micro sprinkler is made by first calculating theoretical analysis and design, and then drawing production drawings. The micro sprinkler is made of plastic mold, trial 5 different nozzle diameter rotary micro-sprinkler with a rotating body of the main orifice flow channel elevation angle of $30^{\circ}$ and the vice orifice flow channel elevation angle of $22^{\circ}$ (Figure 1). According to the industry standard of the People's Republic of China SL / T 67.3-94 [10] regarding the micro-nozzle performance test methods, the spray performance and the range of the different orifice diameter mocro-sprinkler are tested. The experiment was carried out at Hohai University

Jiangning Campus of water resources hall under no wind conditions. The test equipment is a small flow pump, two filters are installed at the pump outlet. Before and after the filter installed a pressure gauge, about 10 meters $\varphi 25 \mathrm{~mm}$ PE pipe installed behind it, and then connected a period of hose about $0.7 \mathrm{~m}$ with the nozzle. The micro-sprinkler stuck in the ground with a $50 \mathrm{~mm}$ plunger, pressure gauge is adjusted to the rated pressure $200 \mathrm{kPa}$, take the single nozzle spray experiment one by one. Measured the spraying point catchment within 2 hours, using surfer software to draw water distribution[11], relative to the traditional method of drawing, surfer drawing can be made more accurate, and thus the error is smaller, which corresponds to a different nozzle diameter micro sprinklers water distribution shown in Figure 4. The internal solid line circle is the effective range. Comparative analysis of experimental values with the theoretical and simulation value is shown in Figure 5. 

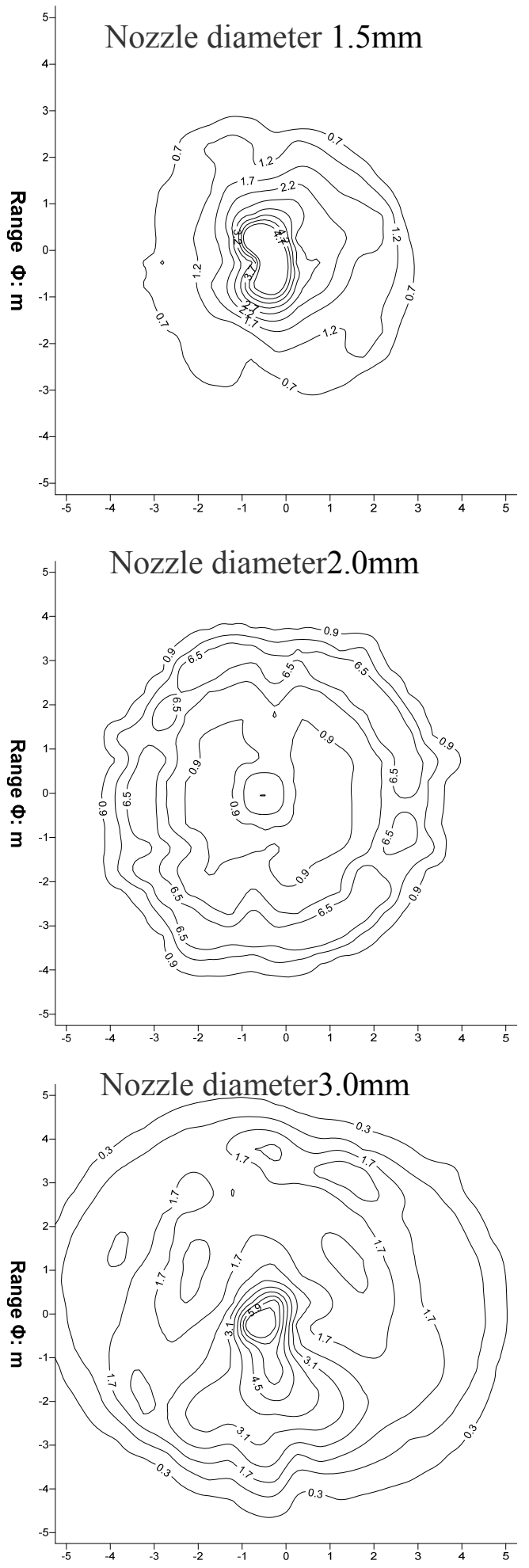
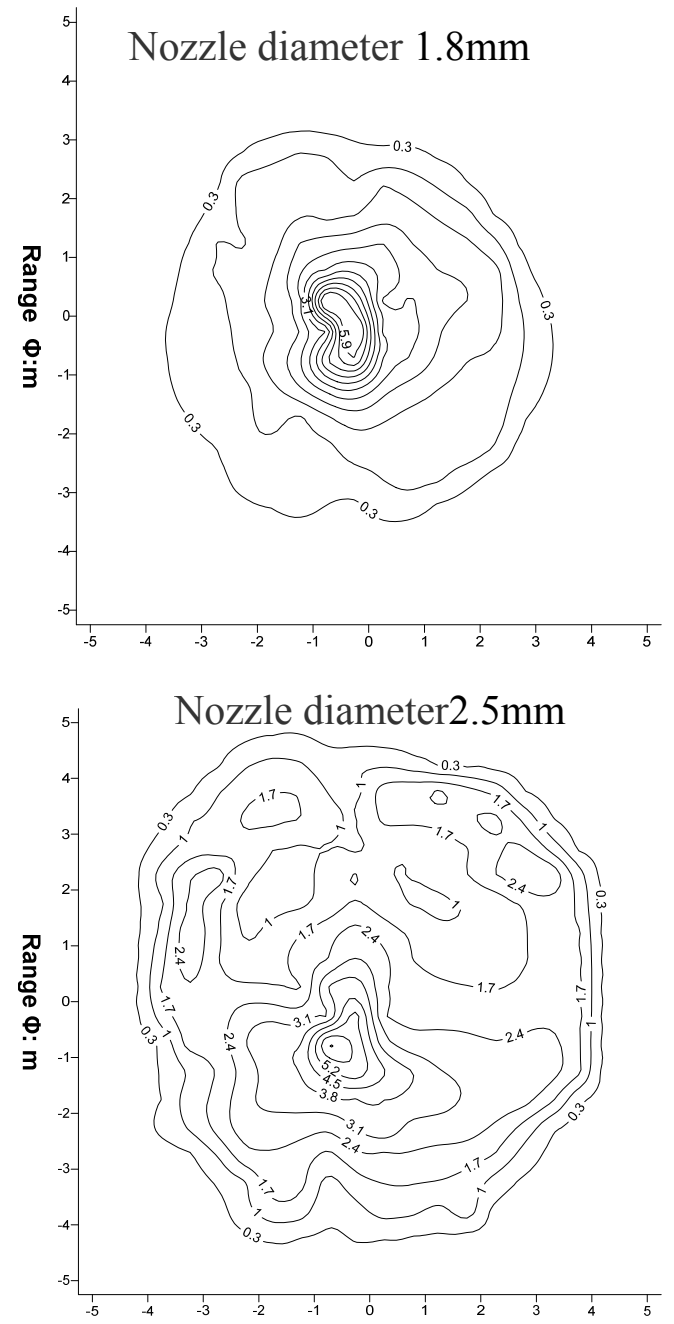

Figure 4 Water distribution under different nozzle diameter

Figure 4 shows that the rotation micro-sprinkler's range of water distribution is relatively large. When the micro-spray nozzle hole diameter increases, the effective spray diameter increases, suggesting that increasing the nozzle diameter reasonably will effectively increase the range of micro sprinklers.

From Figure 5, theoretical calculation of the micro-sprinkler's range gradually increases with the increase of the diameter of the nozzle, consistent with the trend seen in the measured micro-sprinkler's spray rate. However, the ends of the curve have a larger deviation, the big end is greater than the small end, there is an overlap in the middle, when the nozzle diameter is $1.8 \mathrm{~mm}$ and 
greater than the small end, there is an overlap in the middle, when the nozzle diameter is $1.8 \mathrm{~mm}$ and $2.0 \mathrm{~mm}$, the relative error become as small as $1.7 \%$ and $3 \%$, when the nozzle diameter is $1.5 \mathrm{~mm}$ and $2.5 \mathrm{~mm}$, the relative error become is $1.7 \%$ and $3 \%$, when the nozzle diameter comes to $3.0 \mathrm{~mm}$, the relative error become as large as $15 \%$. When the flow becomes large, the error increases, and we believe that there are three reasons as listed in the following: Firstly, because of the big nozzle diameter, the flow water creates a bigger force to the rotary wheel, the rotary wheel's upper parts produces a relatively large resistance with connecting parts. This compels the flow kinetic energy loss to become larger, and affects the actual range; Secondly, as the quantity of flow in the rotary wheel increases its turbulent strengthen, the role of the turbulent to the water pressure dissipation capability also strengthens, thus affecting the actual range; Thirdly, with respect to the drawing size, there is a certain error in the machining of the actual product. During experimentation, the distance between the pressure tester and the nozzle creates some error. In fluent simulation, the ideal state ignores the frictional resistance between the bracket and the rotating body, and the role of resistance the side wall give to the flow and the turbulence. Lastly, measured value is less than the theoretical simulation value.

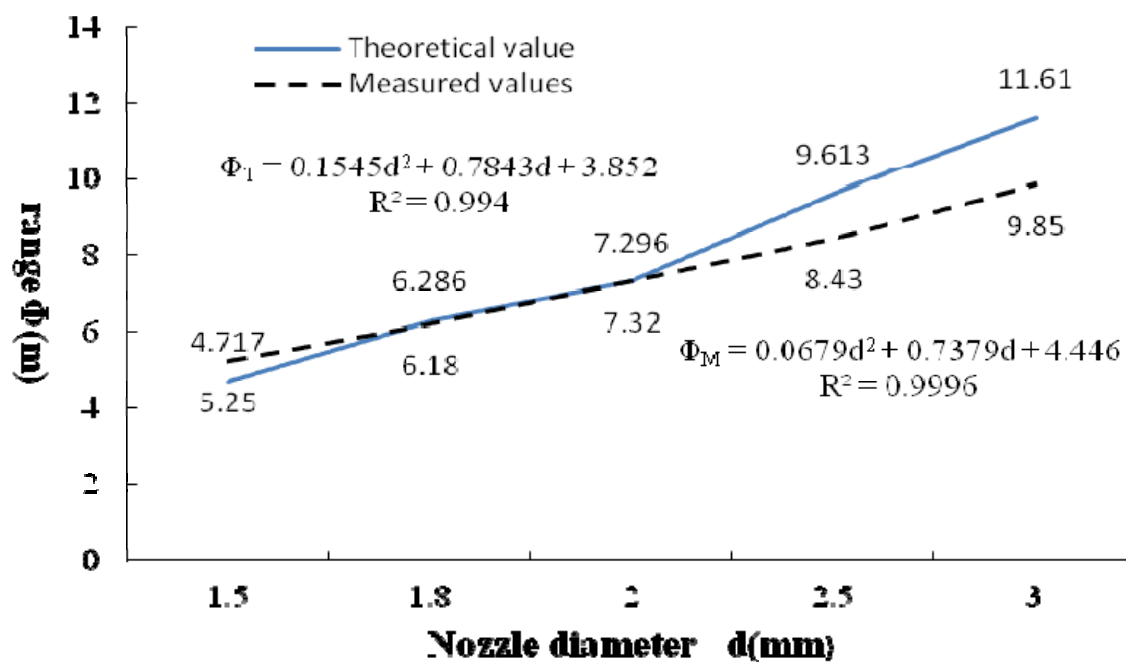

Figure 5 Comparison the measured values and the calculated values range of Micro sprinkler with different nozzle diameter

\section{Conclusion}

The authors simulated the flow movement law inside the big rotary wheel micro-sprinkler effectively by the fluent fluid dynamics simulation software, obtained the speed at the outlet of rotating body, analyzed the droplet movement after export through the theoretical by Newton's second law and the principle of aerodynamics, and thus were able to calculate the range of micro sprinklers effectively. From the law and fitting equation, it can be concluded that the range of the micro sprinkler increases when the nozzle diameter or the outlet elevation angle increase. The mold trial of products was experimentally validated, the result error between measured value and calculated value is smaller in the small nozzle diameter but greater in the relatively large one. Although qualitative analysis has caused the error, but due to the restrictions on time and money, quantitative detailed study cannot be used widely. That is the question that needs to be projected and further researched. Although there are some error in the theoretical simulation and physical testing, the trend is the same. So we can use this method to predict such micro-sprinkler's range. The theory can provide a certain theoretical basis for the micro-sprinkler to research and design of range. The rotary wheeled micro sprinklers have been practically applied in Lianyungang Modern Agricultural Park, 50 acres of nursery areas and other places, and have met the need of irrigation in the nursery better. 
We would like to acknowledge the financial sport from the Science and Technology Support Program of Jiangsu Province, under Contact of BE2009 392.

\section{References}

[1] Zai Songmei,Zhai Guoliang,Development and performance testing of the rotation decline nozzle [J],Water-saving irrigation, 2008(7);20 23

[2] Jin Yongkui,Fang Buling,Development of a new type of micro-sprinklers, China Rural Water and Hydropower 2004(9);51 53

[3] Li Hong, Liu Meng, Research and development of micro sprinklers and a large range of micro-sprinklers Chinese Society of Agricultural Machinery 2006 Annual Conference Proceedings; 139 142

[4] Silva L G et al Modeling Evaporation and Microclimate Changes in Sprinkler Irrigation: Model Assessment and Application Transaction of ASAE 1988 31(5):1487 1493

[5] Thompson A L et. al A Sprinkler Water Droplet Evaporation and Plant Canopy Model :Model Development Transaction of ASAE 1993 36(4) :735 741

[6] Tuo Yunfei, Yang Luhua.The study of sprinkler's range by theoretical formulas and experimental [J]. Journal of Agricultural Engineering,2006,22(1):23 26.

[7] Wang Bolei, Ma Xiaoyi, Modeling and Experiment Validation on the Rotational Sprinkler Nozzle Range,Journal of agricultural machinery, 2008-5,39(5),36 40)

[8] Kincaid D C. Volumetric water droplet evaporation measurement [J].Transactions of the ASAE 1989 32(3):952 927.

[9] Liu Haijun, Gong Shihong. Sprinkler irrigation water droplet evaporation research[J], water-saving irrigation,2000(2);16 21

[10] The People's Republic of China industry standard, SL/T 67.1 3-94.

[11] Yang Luhua,Liu Yuchun,analysis spray (micro) irrigation uniformity through the application of surfer software[J],water-saving irrigation,2004(5),14 16 